\title{
Para sair das margens da história:* classes subalternas e insurgências populares nas pistas de Gramsci
}

\section{Fleeing the margins of history: subordinate classes and popular insurrections in Gramsci's rootprints}

Katia I. Marro ${ }^{a}$

(D) https://orcid.org/0000-0001-8644-8508

Resumo: A partir da leitura de Gramsci em torno da subalternidade, destacamos aspectos conceituais e critérios metodológicos de uma categoria de análise extremamente útil para decifrar a movimentação das classes subalternas nos marcos dos antagonismos de classes. Trata-se de uma perspectiva teórico-metodológica e política fundamental para compreender o significado diferenciado de expressões de rebeldia imediata ou de movimentos políticos e populares mais orgânicos, no contexto de processos de hegemonia.

Palavras-chaves: Classes e grupos subalternos. Subalternidade. Lutas sociais. Insurgências populares.
Abstract: From the reading of Gramsci about subalternity, we highlight conceptual aspects and methodological criteria of an extremely useful analytic category for deciphering the movement of subordinate classes within the framework of class antagonisms. It is a fundamental theoretical-methodological and political perspective to understand the differentiated meaning of immediate rebellion expressions or of more organic political and popular movements, within the context of the hegemonic processes.

Keywords: Classes and subordinate groups. Subalternity. Social struggles. Popular insurrections. 


\section{Introdução}

$\mathrm{N}$

o caminho multidimensional oferecido pela leitura dos Cadernos do cárcere, é instigante a valorização gramsciana dos impulsos de rebelião ou dos "traços de iniciativa autônoma" dos de baixo. Gramsci buscou com sua incansável lupa de pesquisador integral os movimentos dos subalternos nas margens da história, na perspectiva de superação do seu cerco: como movimentos populares de massas que assumem o desafio de construção da hegemonia. Sua obra nos oferece um conjunto de critérios metodológicos, mas também inúmeras passagens de interpretação da atuação das massas trabalhadoras e camponesas da Itália, onde observamos esses instrumentos em pleno funcionamento. Não sempre com uma delimitação teórica unívoca; por momentos, mais próximo de um trabalhador manual que busca os instrumentos para desbravar a realidade, mas com a certeza de quem procura as forças subjetivas dos processos históricos. Teve como referência inabalável o protagonismo das massas trabalhadoras, de cuja trincheira organizativa fez parte como dirigente. ${ }^{1}$

Neste trabalho, deter-nos-emos a "abrir" este instrumento conceitual, tendo como referência o seu tratamento nos Cadernos e um conjunto de interpretações oferecidas por diversos intelectuais que se movimentam no universo teórico e político do marxismo, do qual Gramsci fez parte.

Por que reivindicamos esta chave de interpretação para reconstruirmos os movimentos das classes subalternas? É possível deduzir a categoria de "subalterno" dos Cadernos do cárcere como uma referência importante para o debate que propomos: ela é de extrema utilidade

\footnotetext{
Tanto sua experiência nos conselhos de fábrica protagonizados pelo movimento operário turinense quanto sua posterior vivência como destacado dirigente comunista - sempre imerso no movimento concreto da classe - aparecem na sua obra (de juventude, mas também na obra carcerária) como uma valorização da autoatividade das massas, da importância dos órgãos e instituições próprias da vida operária onde os trabalhadores exercitariam sua autonomia e sua capacidade de auto-organização (e autogoverno), na sua condição de produtores.
} 
porque tem uma amplitude e uma espécie de mobilidade (interna) que nos permitem identificar, valorizar, decifrar e compreender momentos diferenciados da atuação desses grupos - "fases" do grau de consciência histórico-político - nos marcos do desafio da luta hegemônica. Ao repassar a história dos grupos subalternos, Gramsci não constata de forma inamovível a dominação, nem celebra identidades coaguladas, pois a subalternidade é um estado a ser superado. Os autores que trabalharemos confluem na análise de que a categoria de classes subalternas se apresenta também como uma dimensão acrescentada na análise das classes e até da própria luta de classes, podendo funcionar como um instrumento conceitual mais abrangente para compreender momentos e sujeitos diferenciados do antagonismo de classes.

Há algo do contexto histórico em que nasce esta pergunta pelos movimentos das classes subalternas na obra de Gramsci que merece nossa atenção. Ele se pergunta pelos sujeitos do antagonismo de classes - talvez intuindo uma futura mutação no perfil da classe operária ${ }^{2}$ - e pela forma particular que ganha a luta de classes na Itália com a interrogação: por que perdemos? ? $^{3}$ A pergunta vai ecoar no confinamento da prisão fascista e será motor da ânsia de conhecer o mundo dos subalternos na perspectiva da sua expressão antagônica. Daí a importância da perspectiva da subalternidade para decifrar a diversidade dos grupos subalternos, mas também para os momentos de derrota e de refluxo dos movimentos (Modonesi, 2010), para compreender seus motivos e suas consequências, sendo fundamental para reabrir o confronto hegemônico nos tempos futuros.

2 Tal como sugere Del Roio (2018, p. 199), ao pensar na reflexão retratada em Americanismo e fordismo, de Gramsci.

3 Com essa pergunta, Gramsci aponta os limites derivados do não conhecimento da estrutura socioeconômica, assim como da história das classes trabalhadoras e camponesas da Itália. A derrota estaria relacionada com a ausência de autoconsciência crítica do próprio movimento, com sua posição e dificuldade de desenvolver uma nova concepção de mundo que impregnasse nas massas. Daí a sua aposta no conhecimento de uma história integral dos movimentos e iniciativas independentes dos grupos subalternos (cf. Green, 2016, p. 67). 


\section{Abrindo os conceitos: para reconstruirmos os movimentos das classes subalternas}

“Nos arredores de Sevilla, inverno de 1936: aproximam-se as eleições espanholas.

Um senhor está percorrendo suas terras, quando um mendigo se atravessa no seu caminho.

Sem descer do cavalo, o senhor o chama e põe na sua mão uma moeda e uma cédula eleitoral.

O homem deixa cair as duas, a moeda e a cédula, e dando as costas fala:

- Na minha fome, mando eu."

(Eduardo Galeano, Perigo no caminho)

Reconstruiremos algumas reflexões de Gramsci em torno da subalternidade, privilegiando sua abordagem como fenômeno de classe, que remete a processos coletivos e sociais (Liguori, 2011; 2015). Importante observar que não se trata de um conceito indiferenciado, que possa ser igualado a "grupos oprimidos" ou "dominados", muito menos equalizado a "identidades diversas". Sua vida fragmentada é expressão da situação de exploração e opressão em que se encontram, por isso não se trata de uma condição a ser preservada ou afirmada, mas superada hegemonicamente. ${ }^{4}$

\subsection{Quem são as classes e os grupos subalternos? Pensando algumas das suas determinações}

No texto de Gramsci, as classes subalternas comparecem de forma diferenciada, constatando-se, na leitura de Liguori (apud Del Roio, 2017), momentos em que o termo "subalterno" sofre uma extensão e ampliação. Ao nos depararmos com as fragmentárias notas sobre os grupos subalternos nos Cadernos do cárcere, pareceria que Gramsci está ensaiando um conceito de classe que tem de ser amplo o suficiente para dar conta da diversidade

4 Durante (apud Del Roio, 2017); Del Roio (2018). 
(na sua composição objetiva), mas também útil para captar impulsos de rebeldia diferenciados nas massas trabalhadoras e camponesas.

Como aparece o conceito no texto gramsciano? Como fenômeno de classe e coletivo, Liguori $(2011 ; 2015)$ destaca duas acepções: a) como um conceito que nos permite pensar em segmentos de classe diferenciados que ainda não são hegemônicos (desde segmentos de classe fundamentais, como o proletariado industrial, até segmentos de classe marginais e periféricos); b) como um termo dialeticamente vinculado e oposto ao "dominante": classes subalternas em oposição direta ao conceito de classe dominante. Ao pensar nos grupos subalternos, Gramsci observa simultaneamente, sob o mesmo instrumento conceitual, uma diversidade de relações de classes: desde os camponeses e trabalhadores agrícolas - esquecidos pela ausência de uma reforma agrária durante o Risorgimento, submetidos a diversos sistemas de exploração da terra (Boothman apud Del Roio, 2017) — até os operários do coração industrial turinense. Classes subalternas marginais e classes subalternas fundamentais, nos termos de Liguori (2015).

Ao mesmo tempo, nosso intelectual também está interessado em decifrar os processos de subordinação, ao delimitar o termo num campo oposto (mas dialeticamente vinculado) ao dos grupos "dominantes". 0 interessante é que esses processos de subordinação acontecem dentro e para além do lócus da produção, atingindo grupos sociais subalternos - camadas sociais que não podem ser definidas como segmentos de classe propriamente ditos, nos termos de Del Roio (2018, p. 196) - que tendem a sofrer a iniciativa da hegemonia burguesa. Mas é nas brechas da experiência da subordinação que surgem os diversos impulsos de rebeldia e os elementos de antagonismo social desse heterogêneo mundo popular - pois trata-se de segmentos com diversa capacidade de auto-organização e autoconsciência.

O conceito de subalterno permite centrar a atenção nos aspectos subjetivos da subordinação num contexto de hegemonia: a experiência subalterna, isto é, a incorporação e aceitação relativa da relação de mando - obediência, e 
ao mesmo tempo, sua contraparte como resistência e negação permanente (Modonesi, 2010, p. 37, tradução nossa).

Um mesmo conceito reflete tanto a preocupação de dar visibilidade a um conjunto diversificado de segmentos da classe que têm em comum o fato de não serem hegemônicos, e, ao mesmo tempo, os processos de subordinação que os acometem, produzindo inclusive impulsos de rebeldia de radicalidade diferenciada. Como afirma Liguori (2015), com o par hegemônicos/subalternos, Gramsci nos oferece categorias mais abrangentes que entrelaçam melhor a posição social e a subjetividade, o elemento estrutural e o elemento cultural e ideológico. Trata-se de uma perspectiva que permite abordar os explorados e oprimidos em um sentido mais abrangente que as categorias marxistas tradicionais, pois a contradição capital/trabalho se enriquece e se complexifica por meio de muitas determinações, para além dos conflitos do mundo do trabalho.

[...] Gramsci foi além das classes fundamentais do capitalismo e descobriu, no silêncio da história das camadas subalternas, as dimensões culturais que não podiam ser simplesmente incorporadas ao conceito de um proletariado europeu, branco e masculino. Gramsci não abandonava a centralidade operária definida pela inserção nas relações de produção capitalista. A subalternidade era uma dimensão acrescentada, que permitia entrecruzar as diversas formas de sujeição de trabalhadoras e trabalhadores em sentido amplo (Secco apud Del Roio, 2017, p. 16).

Voltaremos nas próximas páginas a essa "dimensão acrescentada" das diversas formas políticas do antagonismo de classe.

\subsection{Como se movimentam as classes subalternas?}

Na tarefa de decifrar as particularidades da luta de classes na Itália (e elaborar uma derrota alimentada do desconhecimento do mundo 
dos subalternos), Gramsci entrelaça elementos estruturais e elementos culturais e ideológicos, e mergulha na sua atuação caótica e episódica - ainda "não dominantes", "não hegemônicos". Longe da pretensão de designar atributos fixos, busca qualificar como se movimentam as classes subalternas: como se rebelam? Podem construir-se como forças antagônicas ao capital? Como superam o estado de subalternidade? Gramsci vai rascunhando características e critérios metodológicos que aparecem às vezes enunciados, às vezes em pleno funcionamento na sua análise das massas populares. ${ }^{5}$

Dada a falta de autonomia dos grupos subalternos, suas iniciativas "defensivas" estão submetidas a leis próprias da necessidade, mais simples, mais limitadas e politicamente mais restritivas do que as leis de necessidade histórica que dirigem e condicionam as iniciativas das classes dominantes (Gramsci, 2002, p. 138).

A história dos grupos sociais subalternos é necessariamente desagregada e episódica. É indubitável que, na atividade histórica destes grupos, existe tendência à unificação, ainda que em termos provisórios, mas esta tendência é continuamente rompida pela iniciativa dos grupos dominantes [...]. Os grupos subalternos sofrem sempre a iniciativa dos grupos dominantes, mesmo quando se rebelam e insurgem: só a vitória "permanente" rompe, e não imediatamente, a subordinação. Na realidade, mesmo quando parecem vitoriosos, os grupos subalternos estão em estado de defesa, sob alerta [...]. Por isso, todo traço de iniciativa autônoma por parte dos grupos subalternos deve ser de valor inestimável para o historiador integral (Gramsci, 2002, p. 135).

Desagreguemos a letra de Gramsci. Os grupos subalternos "sofrem sempre a iniciativa dos grupos dominantes", por isso carecem de

5 Presentes na maioria das vezes como "critérios metodológicos" ou "critérios de método" no Caderno 25 de 1934, intitulado "Às margens da história (história dos grupos sociais subalternos)", compilado no volume 5 da edição que trabalhamos (Gramsci, 2002). Percorremos também outros momentos da obra em que esses conceitos operam na análise concreta de classes e grupos subalternos. 
autonomia; portam necessidades corporativas ("leis próprias da necessidade", "mais simples e limitadas"); encontram-se na defensiva e, portanto, produzem uma trajetória desagregada e episódica, carregada de espontaneísmo. Em outro momento da sua obra ele afirma: “[...] o elemento de espontaneidade é característico da 'história das classes subalternas', aliás, dos elementos mais marginais e periféricos destas classes, que não alcançaram a consciência de classe 'para si' [...]" (Gramsci, 2000b, p. 194). Por sua vez, reconhece que elas se rebelam e insurgem, portam germens de "unificação", ainda que sempre provisória e "rompida pela iniciativa dos grupos dominantes”. A condição de subalternidade se manifesta em oposição dialética à de "dominante" e esse atributo se deve ao fato de não serem Estado (não serem ainda hegemônicas):

A unidade histórica das classes dirigentes acontece no Estado [...]. As classes subalternas, por definição, não são unificadas e não podem se unificar enquanto não puderem se tornar "Estado": sua história, portanto, está atrelada à da sociedade civil, é uma função desagregada e descontínua da sociedade civil (Gramsci, 2002, p. 139-140).

Um segundo elemento a ser observado é o esforço gramsciano de valorização dos "traços de iniciativa autônoma", seja quando se manifestam como expressões mais espontâneas (sobretudo nos seus segmentos marginais e periféricos), seja como insurgências com potencialidades de unificação e de construção de outra hegemonia. Numa busca cuidadosa dos impulsos de autonomia presentes no mundo popular, na sua variada radicalidade, constata: “Existe, portanto, uma 'multiplicidade' de elementos de 'direção consciente' nestes movimentos, mas nenhum deles é predominante ou ultrapassa o nível [...] do 'senso comum'” (Gramsci, 2000b, p. 194). E ao voltar à experiência do movimento turinense, afirma: “Este elemento de 'espontaneidade' não foi negligenciado, menos ainda desprezado: foi educado, orientado, [...] para torná-lo homogêneo em relação à teoria moderna, mas de modo vivo, historicamente eficiente" (Gramsci, 2000b, p. 196). As classes subalternas fundamentais (por 
meio do seu instrumento político) teriam a função de dar uma direção consciente aos movimentos espontâneos, tornando-os "um fator político positivo" (Gramsci, 2000b, p. 197), para romper com a subalternidade e evitar possíveis cenários de reação. ${ }^{6}$

Uma terceira observação sobre esta "lupa" que vai buscar momentos de antagonismo e impulsos potenciais de rebelião nas mais variadas expressões culturais das massas, valorizando âmbitos de subjetivação cuja politicidade não costumava ser reconhecida (Modonesi, 2010). Não por casualidade afirmará que toda relação de hegemonia é uma relação pedagógica. Ao mergulhar na ideologia das classes subalternas, nas formas contraditórias como estas constroem sua identidade de classe, vai se perguntar pelo "núcleo sadio do senso comum"; pelo significado da cultura popular e do folclore; da religiosidade; da linguagem; dos "elementos da psicologia popular"; sobre "as aspirações mais elementares e profundas dos grupos subalternos". Se as massas "sentem" e "raciocinam com a experiência", é mergulhando nela que o historiador integral pode compreender e extrair pistas para a construção de novas relações hegemônicas: não para celebrá-las na sua expressão desagregada, mas para elevá-las, promovendo o seu progresso através de uma reforma intelectual e moral que desfaça o domínio ideológico da burguesia.

O elemento popular "sente", mas nem sempre compreende ou sabe; o elemento intelectual "sabe", mas nem sempre compreende e, menos ainda, "sente". [...] $\mathrm{O}$ erro do intelectual consiste em acreditar que se possa saber sem compreender e, principalmente, sem sentir e estar apaixonado (não só pelo saber em si, mas também pelo objeto do saber), isto é, em acreditar que o intelectual possa ser um intelectual (e não um mero pedante) mesmo quando distinto e destacado do povo-nação, ou seja, sem sentir as paixões elementares do povo, compreendendo-as e, portanto, explicando-as

6 "Ocorre quase sempre que um movimento espontâneo das classes subalternas seja acompanhado por um movimento reacionário da ala direita da classe dominante” (Gramsci, 2000b, p. 197).

7 Dias (apud Del Roio, 2017, p. 73). 
e justificando-as em determinada situação histórica, bem como relacionando-as dialeticamente com as leis da história (Gramsci, 1999, p. 221).

Como bom intelectual orgânico das classes subalternas, compreende que a criação de uma cultura (e de uma subjetividade) antagônica - a "conquista coletiva de um mesmo clima cultural" (Gramsci, 1999, p. 399) - é um momento central na luta anticapitalista.

Criar uma nova cultura não significa apenas fazer individualmente descobertas "originais"; significa também, e sobretudo, difundir criticamente verdades já descobertas, "socializá-las" [...] transformá-las em base de ações vitais, em elemento de coordenação e de ordem intelectual e moral (Gramsci, 1999, p. 96).

Uma quarta observação diz respeito aos critérios metodológicos que nos oferece, apontados como uma "lente" para qualificar as fases através das quais os grupos subalternos poderiam adquirir autonomia. Gramsci nos convida a estudar o desenvolvimento deles a partir de um roteiro de análise que contempla sua existência objetiva; suas diferenciações internas; sua representação política; os níveis de politização e organização (Gramsci, 2002, p. 140).

Para identificar esse "grau de consciência histórico-político a que estas forças inovadoras chegaram progressivamente", são necessários dois parâmetros: a) investigar e identificar as fases através das quais se adquire autonomia em relação aos inimigos ("separação"); b) adesão dos grupos que as ajudaram ativa e passivamente, ou seja, a capacidade de "unificar em torno de si o povo" (Gramsci, 2002, p. 141). Dessa forma, ao analisar o significado da atuação das classes subalternas, Gramsci identifica momentos diferenciados de extrema utilidade para compreender as lutas sociais: a) valoriza os núcleos de contestação a partir do chamado "espírito de cisão": as faíscas do descontentamento popular, as rebeliões e insurgências, dando visibilidade às suas reivindicações concretas, mas buscando elevar os núcleos de direção consciente presentes 
nas manifestações mais espontâneas; b) aponta a necessidade da sua expressão antagônica: portanto, sua capacidade de "separação" dos grupos dominantes; c) busca compreender sua capacidade de unificação em torno de si (conformando movimentos de massas), isto é, sua capacidade de direção hegemônica em relação a outros grupos: "entre os grupos subalternos, um exercerá ou tenderá a exercer uma certa hegemonia através de um partido" (Gramsci, 2002, p. 140).

Este processo aparece sintetizado numa passagem clássica:

O que se pode contrapor, por parte de uma classe inovadora, a este complexo formidável de trincheiras e fortificações da classe dominante? 0 espírito de cisão, isto é, a conquista progressiva da consciência da própria personalidade histórica, espírito de cisão que deve tender a se ampliar da classe protagonista às classes ainda potenciais: tudo isso requer um complexo trabalho ideológico [...] (Gramsci, 2000a, p. 79).

Ele aborda o mesmo problema desde outra perspectiva, ao analisar momentos diferentes na "relação de forças" políticas, propondo avaliar o grau de homogeneidade, de autoconsciência e de organização alcançado pelos vários grupos sociais, oferecendo-nos um parâmetro para analisar os diversos momentos da consciência política coletiva dos grupos subalternos.

Finalmente, temos aqui algumas observações importantes a fazer, que se relacionam com a tradição política e teórica da qual Gramsci fez parte. Elas permanecem como desafios para a atualidade, ainda que em condições históricas radicalmente diferentes: a subalternidade é um estado a ser superado, tendo como premissa a necessária unificação das classes subalternas por meio de um instrumento político que "costure" esta universalidade e as prepare para a luta pela hegemonia, para a conformação de um novo Estado (e sua posterior extinção). Vamos desagregar esta afirmação em todos os seus significados.

A subalternidade é um estado a ser superado, sendo necessários instrumentos e momentos de unificação das classes subalternas numa 
chave de classe. Não parece haver em Gramsci nenhuma pretensão de uniformização dos sujeitos diversificados que as compõem, mas é evidente que sua autonomia só pode ser exercida na unidade, para neutralizar as tendências de cima que buscam sua abolição e esterilização (Secco apud Del Roio, 2017); para dissolver os mecanismos de subordinação que as mantêm na fragmentação e as desarmam para as lutas pela hegemonia. As classes subalternas se rebelam, mas isso não basta; daí a necessidade dos elementos de "direção consciente" proporcionados pela experiência do partido político de classe. Este instrumento jamais poderia ser uma "direção arbitrária" ou uma estrutura separada, mas deveria emergir de uma relação dialética com as massas (uma dialética partido-movimentos) (Liguori, 2015). Como processo educativo, a vida coletiva e auto-organizativa da classe alimentaria o movimento partidário, delineando um instrumento que se estruturaria a partir das lutas sociais das massas trabalhadoras. Teria a função de dirigente e educador das massas, mas originado e educado pelas massas das quais é produto. Funcionaria como um instrumento capaz de canalizar a rebeldia dos subalternos, costurando os impulsos de recusa da ordem, promovendo uma reforma intelectual e moral que negue a subalternidade, unindo e liderando uma aliança de classes e grupos sociais. ${ }^{8}$

[...] embora seja verdade que os partidos são apenas nomenclaturas das classes, também é verdade que os partidos não são apenas uma expressão mecânica e passiva das próprias classes, mas reagem energicamente sobre elas para desenvolvê-las, consolidá-las, universalizá-las (Gramsci, 2000b, p. 201).

"Nomenclatura de uma classe" significa que o partido é um órgão da classe, é parte da classe, é parte dos movimentos subalternos: parte do estado de conhecimento das massas para elevá-lo (Liguori apud Semeraro

8 Cf. Green (2016); Schlesener (apud Del Roio, 2017); Del Roio (2018). 
et al., 2013). Instrumento necessário para construir aquela fase mais estritamente política da correlação de forças, oferecendo homogeneidade e autoconsciência nas lutas.

Os impulsos de rebeldia presentes nas classes subalternas são compreendidos no contexto das lutas pela hegemonia. Elas podem produzir insurgências e rebeldias, mas devem organizá-las; torná-las orgânicas; prepará-las na sua disposição para a luta (superando o espontaneísmo); investindo para a sua consolidação como movimentos de massas. Isso significa, na própria letra de Gramsci, que a "luta ferve" não no plano meramente corporativo, mas político-universal - em que se exigem qualidades excepcionais de paciência e espírito inventivo. Qualidades a serem exercitadas nas fortalezas e casamatas que resguardam a hegemonia burguesa por meio da guerra de posição (Gramsci, 2000b). ${ }^{9}$ Trata-se de uma luta que exige a progressiva elevação intelectual das massas e a organização dos subalternos em classe; daí o papel pedagógico desenvolvido por movimentos, partidos e demais instrumentos organizativos. Entre os impulsos de rebeldia e as lutas pela hegemonia há um longo caminho que deve ser aberto na chave da "correlação de forças políticas", da qual já falávamos.

Para sair das margens da história, as classes subalternas devem tornar-se Estado. Dizíamos que classes subalternas são um conceito oposto

9 É interessante observar que em Gramsci guerra de posição e guerra de movimento não encontram uma relação dicotômica nem excludente. Tal como lembra Del Roio (2018), a passagem da guerra de movimento (do ataque frontal) para a guerra de posição expressa uma mudança na forma do conflito social, na dinâmica de uma luta de classes que se transmuta na disputa pela hegemonia civil. A expansão de Estados que ingressam na fase imperialista; a superioridade da força armada da burguesia; a ampliação da sua capacidade de incorporar a cultura e as instituições operárias à ordem são alguns dos fenômenos observados por Gramsci ao tratar da fortaleza da hegemonia burguesa e das dificuldades de organização antagônica e autônoma da classe. Daí a aposta numa estratégia de longo prazo centrada na autoeducação das massas, na fermentação de uma cultura antagônica, de uma nova atmosfera intelectual e moral. Na interessante interpretação desse autor, a guerra de posição é uma imposição das classes dirigentes na sua ofensiva contra as forças antagônicas, as quais devem lutar nesse campo para minorar os efeitos da derrota até que se acumule força suficiente para reverter a luta em guerra de movimento (Del Roio, 2018, p. 213). 
ao de classe dominante, em que sua condição estava atrelada a "uma função desagregada da sociedade civil”, ao fato de não serem Estado. Daí que a superar implica o desafio de se tornarem Estado, elaborando uma proposta de reorganização de toda a estrutura nacional e provocando rupturas na sua essência de classe: afirmando a "autonomia integral", aglutinando e unificando em torno de si as diversas forças populares, pondo "as grandes massas populares em contato com o Estado" (Gramsci, 2002, p. 93). Permanecer no nível da sociedade é continuar na subalternidade política e cultural, desagregadas e fragmentadas, é renunciar ao desafio de pensar a hegemonia. ${ }^{10}$

\subsection{Novas determinações na análise das classes e suas lutas para compreender o tempo presente}

A riqueza deste instrumento conceitual deriva de uma dimensão acrescentada na análise das classes e até da própria luta de classes, possibilitando uma abertura categorial que permitiria ampliar e pluralizar estas noções. ${ }^{11}$ Mesmo identificando que "a hegemonia nasce da fábrica”, podemos pensar que há em Gramsci pistas para compreender o movimento das classes subalternas muito além do lócus da produção, dando visibilidade aos processos de subordinação que operam na disputa pela hegemonia. Tal como afirma Secco (apud Del Roio, 2017), Gramsci permitiu a ampliação da classe porque os subalternos estão para além do espaço da dominação fabril, daí que no contexto estrutural da exploração

10 Cf. Simionatto (2009); Liguori (2011; 2015); Semeraro et al. (2013).

11 Com ênfases diferenciadas, essa percepção está presente em Liguori (2011; 2015); Semeraro et al. (2013); Del Roio (2017; 2018); Secco (apud Del Roio, 2017), entre outros estudiosos do seu pensamento. Mattos (2019) identifica que o sujeito histórico transformador presente em Marx e Engels é diverso, heterogêneo e constituído historicamente, não podendo ser interpretado como um resultado direto das relações de produção. Ainda que essa percepção seja acertada, resulta inegável que, com poucas exceções, durante algumas décadas prevaleceram no âmbito do marxismo análises mais estreitas do fenômeno das classes e da luta de classes. 
capitalista (e da subordinação econômica) possamos compreender outras formas de sujeição que atingem diversos grupos sociais explorados e oprimidos.

Vale a pena um pequeno parêntesis sobre a ampliação da noção de classe proporcionada pela análise gramsciana. Não restam dúvidas de que é cada vez mais necessário operar com uma noção de classe que expresse a diversidade da sua composição atual - atrelada a formas de exploração do trabalho muito diferenciadas, mas que se inserem no mesmo circuito de produção do valor. Mas também é necessário compreender, tal como aponta Mattos (2019, p. 33) na trilha de Bensaïd, que o estudo da classe não pode se reduzir à simples oposição de interesses entre capital e trabalho na produção. Deve reconhecer que a classe trabalhadora está constantemente sendo "feita" e "refeita" com experiências que definem sua existência dinâmica (numa chave thompsoniana). É decifrar, numa perspectiva de totalidade, os circuitos de exploração e expropriação que produzem diversos antagonismos sociais. Gramsci nos permite acrescentar outro elemento, na medida em que ao problematizar a subalternidade nos remete aos efeitos da subordinação ao capital para além da esfera da produção e, portanto, atingindo também grupos sociais expropriados e oprimidos para além da sua condição de trabalhadores (ou força de trabalho).

A partir dessa chave analítica seria um equívoco compreender conflitos, lutas e movimentos sociais que não derivam diretamente do mundo da produção, desvinculados da dinâmica da sociedade de classes, ou considerar apenas dimensões culturais da opressão e da identidade dos subalternos sem reconstruí-los no seio dos antagonismos de classes. Mas também seria um equívoco pensar que as lutas dos subalternos poderiam ter um "lugar secundário" em relação à luta de classes, como se suas reivindicações pudessem ser resolvidas sem antagonismo com o capital (Secco apud Del Roio, 2017). Por exemplo, as lutas das mulheres contra o patriarcado não deveriam ser compreendidas como "externas" ou "secundárias" em relação às lutas de classes: se as lutas feministas 
desnudam que a exploração do trabalho reprodutivo é um momento central para o capital, elas podem produzir uma consciência teórica importante não apenas para as mulheres, mas essencial aos processos de construção de uma reforma intelectual e moral. É a aposta por compreender os movimentos feministas no campo das relações de hegemonia (cf. Durante apud Del Roio, 2017).

Encontramos em Gramsci ${ }^{12}$ pistas que nos permitem compreender momentos e sujeitos diferentes do antagonismo de classes que fazem parte de uma mesma totalidade - e não sempre aparecem de forma articulada na consciência e na prática histórica dos subalternos. Por exemplo, apesar da "interpendência dialética" (como nas interpretações de Clóvis Moura) entre os processos de colonização de América Latina e a acumulação primitiva que alavancou a ascensão do modo de produção capitalista, raramente reconstruímos a simultaneidade dialética de diversos sujeitos que foram capazes de desnudar e enfrentar expressões diferentes dos antagonismos de classes, seja na "periferia", seja no coração do capitalismo central: distantes geograficamente; com formas políticas e sujeitos diferentes; mas simultâneos e parte da mesma totalidade da exploração capitalista. José Carlos Mariátegui foi outro intelectual que refletiu nessa mesma direção ao atrelar a subalternidade dos indígenas ao problema da terra (à estrutura fundiária e à particularidade das relações de classe no Peru), operando com uma noção ampliada de classe. É por esse motivo que a noção de classes e grupos subalternos pode ser muito

12 De fato, no Caderno 25 (Gramsci, 2002, p. 138), Gramsci usa este conceito para compreender escravos e servos da antiga Roma, assim como trata de Lazzaretti (um rebelde primitivo do século XIX, líder de uma seita popular herética nos primórdios da constituição da República), utilizando-o seja como sinônimo de classes fundamentais ou para retratar os impulsos de rebeldia elementares que emergiam entre os camponeses (cf. Liguori, 2015). Esse uso expressa certa extensão analítica no tempo e no espaço (nos termos de Del Roio, 2018), que pode ser de extrema utilidade para compreender a história e a atualidade das insurgências populares da América Latina. Secco (apud Del Roio, 2017) também identifica uma espécie de tradução espacial, já que a subalternidade retrataria as "periferias" no conjunto de classes oprimidas que habitavam o Mezzogiorno. 
útil para compreender sujeitos coletivos, característicos da "periferia" capitalista, apresentando confluências importantes com movimentos e insurgências populares históricas ou contemporâneas.

\section{Como sair das margens da história? Algumas conclusões provisórias}

Neste texto, buscamos mostrar que a reflexão gramsciana em torno das classes subalternas é de extrema utilidade para decifrarmos o universo das insurgências populares na direção da construção de processos de hegemonia. Trata-se de uma perspectiva teórico-metodológica e política fundamental para quem quer compreender expressões de rebeldia imediata; a organização dos movimentos populares; refletir sobre o significado dos processos de autoeducação e elevação intelectual das massas. Mas nos alerta também sobre os riscos da sua "essencialização", como se sua capacidade de contestação fosse automática em relação a conflitos e antagonismos (Modonesi, 2010).

Gramsci nos inspira a pensar que o trabalho "manual" do historiador integral é o de quem reconstrói essas subjetividades coletivas à luz das lutas, mas imersas na contraditória experiência da dominação - nos meandros das relações entre rebeldia e obediência. É apostar no conhecimento das classes subalternas partindo dos seus impulsos de rebeldia imediata, indagando sua capacidade político-organizativa em potencial; a capilaridade das suas lutas nos territórios e nas periferias; identificando a "consciência teórica" presente nas suas atividades; sua potencialidade para a realização da "grande política" (cf. Semeraro et al., 2013).

Afirmávamos também que a reflexão gramsciana sobre as classes subalternas nos oferece uma perspectiva para adentrar na diversidade da classe, podendo iluminar inclusive momentos e sujeitos diferentes do antagonismo de classes que fazem parte de uma mesma totalidade. Ao mesmo tempo, na medida em que ela entrelaça elementos estruturais e 
político-culturais para explicar os processos de subordinação, nos permite reconstruir o movimento das classes subalternas, além do lócus da produção, compreendendo outras formas de sujeição que atingem diversos grupos sociais explorados e oprimidos.

Tem mais. Dizíamos que ela tem certa mobilidade para captar momentos diferenciados no processo de "fazer-se classe" dos grupos subalternos. É ampla o suficiente para nos permitir valorizar desde tímidos traços de iniciativa autônoma até momentos de rebelião e insurreição; porque ela ilumina a necessidade da expressão antagônica dos subalternos (não desprezando os elementos "espontâneos", mas educando-os, orientando-os); porque ela aponta o desafio da construção de movimentos de massas, mas na perspectiva de unificação do conjunto das classes subalternas; porque ela não celebra nem enaltece impulsos de autonomia coagulados, mas indica que para sair das margens da história é necessário romper com a subordinação e assumir o desafio da disputa pela hegemonia; contudo, ela mostra que essa tarefa de unificação se faz a muitas mãos e não é passível de se encastelar na construção política de minorias. Em mais um exercício de balanço do movimento turinense, nosso intelectual afirmava: “Esta unidade de 'espontaneidade' e 'direção consciente' [...] é exatamente a ação política real das classes subalternas como política de massas e não simples aventuras de grupos que invocam as massas" (Gramsci, 2000b, p. 196).

Lutas, movimentos populares e processos organizativos são fundamentais para a unificação das classes subalternas, para a sua constituição como classe, para a realização da reforma intelectual e moral necessária para uma nova hegemonia. É possível também extrair de Gramsci um "roteiro" de estudos para os dias de hoje: preocupações, chaves analíticas e hipóteses de trabalho para indagar o mundo dos subalternos, na perspectiva da sua expressão antagônica. Uma aposta por situar os subalternos no tabuleiro da guerra de posição. Quais os instrumentos organizativos capazes de cumprir esse papel pedagógico? Como reconstruir o espírito de cisão? A partir de que referências culturais e organizativas 
reconstruir a identidade de classe? Quais organismos populares têm condições de arrancar influências regressivas que operam na sociabilidade contemporânea das massas e promover sua elevação cultural? Como dissolver consensos e mobilizações em torno de valores retrógrados que proliferam em tempos de reação? Quem organiza os subalternos? Como se organiza o conformismo social? Em que consiste o aparato cultural da hegemonia burguesa que opera cimentando a subalternidade?

Nesse sentido, é importante voltar a colocar a "lupa" nos elementos de cultura popular, nas expressões de rebeldia espontânea, nos órgãos de auto-organização e nos possíveis momentos de unificação. Mergulhar no universo das insurgências populares para resgatar e valorizar o espírito de cisão, para iluminar os momentos em que os grupos subalternos possam afirmar: "Na minha fome, mando eu!".

\section{Referências}

DEL ROIO, Marcos (org.). Gramsci: periferia e subalternidade. São Paulo: Edusp, 2017.

DEL ROIO, Marcos. Gramsci e a emancipação do subalterno. São Paulo: Fundação Editora Unesp, 2018.

GRAMSCI, Antonio. Cadernos do cárcere. Rio de Janeiro: Civilização Brasileira, 1999. v. 1: Introdução ao estudo da filosofia. A filosofia de Benedetto Croce.

GRAMSCI, Antonio. Cadernos do cárcere. Rio de Janeiro: Civilização Brasileira, 2000a. v. 2: Os intelectuais. O princípio educativo. Jornalismo.

GRAMSCI, Antonio. Cadernos do cárcere. Rio de Janeiro: Civilização Brasileira, 2000b. v. 3: Maquiavel. Notas sobre o Estado e a política.

GRAMSCI, Antonio. Cadernos do cárcere. Rio de Janeiro: Civilização Brasileira, 2002. v. 5: O Risorgimento. Notas sobre a história da Itália.

GREEN, Marcus. Gramsci e as lutas subalternas hoje: espontaneidade e organização política. Revista Outubro: revista do Instituto de Estudos Socialistas, n. 25, p. 53-81, mar. 2016. Disponível em: http://outubrorevista.com.br/wp-content/uploads/2016/03/3_Greentraducao.pdf. Acesso em: 25 jun. 2020. 
LIGUORI, Guido. Tre accezioni di "subalterno" in Gramsci. Revista Critica Marxista, Roma: Dedalo, n. 6, p 33-41, 2011. Disponível em: https://criticamarxistaonline.files.wordpress. com /2013/06/6_2011liguori.pdf. Acesso em: 20 fev. 2020.

LIGUORI, Guido. "Classi subalterne" marginali e "classi subalterne" fondamentali in Gramsci. Revista Critica Marxista, Roma: Dedalo, n. 4, p. 41-48, 2015. Disponível em: http:// igsarchive.org/article/classi-subalterne-marginali-e-classi-subalterne-fondamentali-ingramsci/. Acesso em: 10 fev. 2020.

MATTOS, Marcelo Badaró. A classe trabalhadora, de Marx ao nosso tempo. São Paulo: Boitempo, 2019.

MODONESI, Massimo. Subalteridad, antagonismo y autonomía: marxismos y subjetivación política. Buenos Aires: Clacso; Prometeo, 2010.

SEMERARO, Giovanni et al. Gramsci e os movimentos populares. Niterói: Editora da UFF, 2013.

SIMIONATTO, Ivete. Classes subalternas, luta de classe e hegemonia: uma abordagem gramsciana. Revista Katalysis, Florianópolis: Universidade Federal de Santa Catarina, v. 1, n. 12, p. 41-49, jan./jun. 2009.

\section{Sobre a autora}

KATIA I. MARRo - Doutora em Serviço Social pela Universidade Federal do Rio de Janeiro, pós-doutora em Serviço Social pela Universidade do Estado do Rio de Janeiro. Professora Associada.

E-mail: kmuffro@gmail.com 